\title{
LVII. Answer to W. H. G.'s observations on Mr. Tatum's experiments on vegetation
}

\author{
Mr. J. Tatum
}

To cite this article: Mr. J. Tatum (1817) LVII. Answer to W. H. G.'s observations on Mr. Tatum's experiments on vegetation, Philosophical Magazine Series 1, 50:235, 353-358, DOI: 10.1080/14786441708637792

To link to this article: http://dx.doi.org/10.1080/14786441708637792

曲 Published online: 27 Jul 2009.

Submit your article to this journal $[\pi$

LII Article views: 2

Q View related articles $\asymp$ 
many times to the same process, after having triturated it, and agitated it with the same acid, it first became fluid, afterwards divided into globules, and finally appeared purified mercury similar to that produced by the preceding experiments. Hence it appears that, by the action of sulphuric acid aided by the mechanical division effected by agitation, the adulterated nercury of commerce, and even that which contains a greater portion of extraneous motals, may be purified in a manuer sufficient to serve all the common purposes of experimental philosophy and chemistry. This method does not require continual attention, is not expensive, particularly where the nercury is little altered, and does not expose the operator to any danger.

\section{Ansuer to W. H. G.'s Observations on Mr. Tatum's} Experiments on Vegelation. By Mr. J. Tatum.

\section{To Mr. Tilloch.}

SIR, - Y our correspondent, W. H. G., in reply to the paper I communicated to your Magazine of July, accuses me of "6 unpardonable igiorance for pretending to enlighten one of the most controverted subjects of experimental science, by views and experiments which have been ditailed in half a dozen professed treatises, and otherwise pronulgated in every possible way."

Lucca batlss has published someaccount of them : but, as usual with writers on bat's, his work is more paneggrical and historical than chemical; - a much better account may be expected from his relative Dr. Domen. Yieri, professor of chemistry in the college of Lucca. A very satisfactory ard able analysis of the Pisa bath waters may aiso be expected from the modest and ingenious author of the preceling mernoir; who pirsues the discovery of facts with unremitting zeal, and leaves the development of crude theories to those self-called chemists whose pen, ink, and paper are more useful to them than acids, retorts, and furraces. There are still persons who ascribe these hot-baths to the infuence of volcanoes; but there is not the smallest trace of any thing like volcanic matter, or even any combustible substance, to be discovered within many miles of them; nothing that, either chemically o: geologically speaking, could sanction the belief that they owe their warmth to exhausted subterraneous volcanoes. Vast ridges of mountains surround them, entirely of carbonat of lime or hard and coarse marble, with occasionally veins of felspar, rock crystal, and very rarely traces of tourmaline; but very considerable intersections of these calcareous masses frequently orcur, consisting of various combinations of magnesia and lime, forming all the giadations from the hardest to the most friable schist. Gypsum and pyrites, particularly the former, are of rare occurrence, and never in such quantities as would sanction the conjecture that the caloric developed by the deconposition of the latter might contribute to raise the temperature of these springs. It is true that in the valleys adjoining these hot springs inflammable gas, chiefly carburetted hydrogen, abounds; but whether connected as a cause or an effect is not so easy to determine.

Vol. 50. No. 235. Nov. 1817. 
From which I infer that he imagines I was unacquainted with any of the six authors alluded to : but in this as well as several other particulars he labours under a mistake. I had consulted " the ill-digested experiments of Dr. Ingenhousz," the excellent and truly valuable volumes of $\mathrm{Mr}$. Ellis, and the still more recent publication of Sir Humphry Davy; nor was I quite ignorant that Saussure, Scheele and Sennebier had entered the list of disputants on this controverted subject. But should your correspondent ask, Then why advance opinions in opposition to the "old story of the purification of the atmosphere by vegetation, which had been treated of by others?'” I would answer, that although the opinion is old, it is neither forsaken nor abandoned, nor is it left to sink without a powerful support to rescue it from oblivion: for, notwithstanding W. H. G. marshals the name of that truly excellent philosopher Sir Humphry Davy in the list of the balf dozen who have opposed the old story of Dr. Priestley, and who he says have so long anticipated my opinions, I have no doubt but that, with all my " unpardonable ignorance," I shall be able to prove tlat he has been most egregiously mistaken. I will not retort his own language on Mr.W.H. G., but content myself with remarking, that from the diversity of opinions displayed in the above authors, it was not very unnatural that I should entertain a wish to investigate this controverted subject, and particularly as I thought many of their detailed experiments were not unexceptionable. For example; who can approve of. the effects of detached leaves while confined under pump-water being brought forward as a proof of the effects carried on by an entire and living vegetable while exposed to air? In my experiments I endeavoured to obviate objections of this nature :- -how far I have succeded, I shall leave to others to determine. One of the motives which induced me to comnit their results to your Magazine, was, that during my last course of lectures I was informed by a gentleman attending the lectures of the Surrey Institution, and who was present at my lecture on vegetable chemistry when I introduced some of those experiments, that the then chemical lecturer at that Institution had promised to prove that vegetables improved the atmosphere, but that he had not made good his promise or even attempted it: on which several gentlemen who were present, observing that the experiments militated so materially against the popular opinion, expressed surprise that I did not make them public. Under these circumstances I communicated them to your Magazine.-But to return to your correspondent, who says, “ Dr. Priestley was the person with whom the old story originated; but that even he seems afterwards to have been aware of the inaccuracy of his conclusions:" for he says in vol. iii. p. 273, 
(n) In general the experiments of this year were unfavourable to my former hypothesis; for whether 1 made the experiments with air injured by respiration, buming of candles, or any other phlogistic process, it did not grow better, but worse ; and the longer the plants continued in the air the more phlogisticated it was. I also tried a great variety of plants with no better success." From this one would imagine that W. H. G. thought the Doctor was about to abandon his old opinion : but if he had taken the trouble of turning over one leaf; he would have found the Doctor still firmly maiutaining his "ald story," for he says, "Upon the whole I sitll thought it probable, from the experiments of this year, that the vegetation of healthy plants, growing in situations natural to them, has a salutary effect on the air in which they grow;-for one clear instance of the melioration of air in these circumstances should weigh against a hundred cases in which the air is made worse by it."

Is there here any reason to conclude that the Doctor was " aware of the inaceuracy of his conclusions?" Does not the above prove that, so far from altering his opinion, he was determined to support " his old story" in the strongest possible language?

Your correspondent has seen fit to class Dr. Ingenhousz as well as Sir Humphry Davy among the half dozen authors "who experimentally contradict the above opiniou." Now, as W.H.G. accuses me of "unpardonalle ignorance," surely we ought not to expect him to betray any in his criticisms on me. But let us see what were the experimental opinions which Dr. Ingenhousz promulgated in p. 23 of his prefatory remarks. He says, “The discovery of Dr. Priestley, that plants thrive better in foul air than in cornmon and in dephlogisticated air, and that plants have a power of correcting bad air, has thrown a new and important light upon the arrangement of this world. It shows, even to a demonstration, that the vegetable kingdom is subservient to the animal, and vice vers $\dot{d}$, that the air spoiled and rendered noxious to animals by their breathing it, serves to plants as a kind of nourishment." And at section 16, he says, "In order to put iny conjecture to the trial, I placed at eleven o'clock, in a waim surshine, two jars of an equal size, each containing an equal quantity of sprigs of peppermint in pump-water. In one of these was let up a certain quantity of common air. In the other jar was let up the same quantity of air fouled by respiration: at two o'clock the air of both jars was found much improved; and at four o'clock the common air was still more improved." I shall not make any remarks on the namner in which these experiments were conducted; I merely quote the above to prove that your correspondent has erred (I will not suppose wilfully) in representing Dr. Ingenhousz as " one of the half dozen au- 
thors who experimentally contradicts Dr. Priestley." So far from this being the fact, it appears from the above quotations that he is endeavouring by all possible means to support him: indeed, the whole tenor of his work (so far from contradicting Dr. Priestley) is intended to corroborate the same. I will not occupy your pages by remarks on Scheele, Saussure, or Sennebier, but proceed to Mr. Ellis and Sir H. Davy. Your correspondent cannot approve more highly of the opinions entertained in the tro volumes of the former of these authors than I do. But I think he again labours under a mistake when he represents Mr. Ellis's secoud volume as the last work on the subject ; for my copy bears the date of 1811. But that of Sir $\mathrm{H}$. Dary on agricultural chemistry (which W.H. G. quotes) was published in 1813. Under these circumstances I know not by what means be can consider Mr. Ellis as the last author on the subject. But you will perceive that this is not merely the first, last, or greatest mistake W. H. G. has fallen into: for although Mr. Ellis has ably promulgated the same opinions (Girawn from experiments differently conducted to what mine were) which 1 have since advanced; yet I think it is most unwarrantable and unjustifiable to represent "Sir H. Davy as being convinced that Mr. Ellis had not been deceived by his extensive researches ;" and also of enrolling Sir $\mathrm{H}$. in the list of half a dozen who had experimentally contradicted Dr. Priestley. In order to prove the error of the first statement, I must refer to Sir Humphry's work above mentioned, p. 195, where Sir Humphry says, "Some persons have supposed that plants exposed in the free atmosphere to the vicissitudes of stin-shine and shade, light and darkness, consume more oxygen than they produce; and that their permanent agency upon air is similar to that of animals : and this opinion is espoused by the writer on the subject I have just quoted (Mr. Ellis), in his ingenious Researches on Vegetation. But all experiments brought in favour of this idea, and particalarly his experiments, have been conducted under circumstances unfavourable to accuracy of results."

So far then was Sir Humphry from being convinced that Mr. Ellis was not deceived by his experiments, that he actually condemns his experiments as inaccurate. But to prove the error of the second statement of W.H. G.; namely, of SirHumphry's being one of the "half dozen who experimentally opposed Dr. Priestley's opinion," we need only refer to the latter part of the above page, and also to p. 197. In the first of these Sir H. says, "In some of the carly experiments of Dr. Priestley, before he was accuuainted with the agency of light upon leaves, air that had supported combustion and respiration was found purified by the growth of plants, when they were exposed in it for successive 
days and nights; and his experiments are the more unexceptionable, as the plants in many of them grew in their uatural states, and the shoots or branches from them only were introduced through water into the confined atmosphere." And the next is Sir Humphry's own experiment, p. 197 : "The following experiment I consider as conducted under circumstances more analogous to those existing in nature. A turf four inches square from an irrigated meadow clothed with common meadow grass, meadow fox-tail grass, and vernal meadow grass, was placed in a porcelain dish, which swam on the surface of water impregnated with carbonic acid gas: a vessel of thin flint glass, of the capacity of 230 cubical inches, having a funnel furnished with a stop-cock inserted in the top, was made to cover the grass, and the apparatus was exposed in an open place. A small quantity of water was daily supplied to the grass by the means of the stop-cock. Every day likewise a certain quantity of water was removed by a siphon, and water saturated with carbonic acid gas was supplied in its place, so that it may be presumed that a small quantity of carbonic acid gas was constantly present in the receiver.

"On the 7 th of July 1807, the first day of the experiment, the weather was cloudy in the morning, but fine in the afternoon, the thermometer at $67^{\circ}$, the barometer 30.2. At ten on the morning of the 15 th, I examined a portion of the gas; it contained less than 1-50th of carbonic acid gas, 100 parts of it exposed to the impregnated solution left only 75 parts;" (100 parts of the air of the garden occasioned a diminution to 79 ) "so that the air was four per cent. purer than the air of the atmosphere; another similar experiment was made with equaily decisive result." p. 199. " "These facts confirm the popular opinion" (the old story) "that when the leaves of vegetables perform their healthy functions, they tend to purify the atmosphere, in the common variations of weather, and changes from light to darkness." Are not these principles or opinions the very same as those promulgated by Dr. Priestley? Aye, and by Dr. Ingenhousz too? Yet W. H. G. represents Sir H. as one of the experimental opposers of that very system he is actually adroeating. From these repeated misrepresentations on doctrinal points on the part of W.H.G., it is even difficult to believe that he himself knew which side of the question the above authors maintain. We here see that Sir $\mathrm{H}$, did not consider hirnself as betraying unpardonable ignorance by publishing his "Views and Experiments," although they had been detailed by Drs. Priestley and Ingenhousz, many years before, and of course had "anticipated" his views.

Again. He says, "The question still remaining is, not whether plants have the power of counteracting the vitiation produced 
by the breathing of animals; but whether they are able, during sunshine, to reconvert into oxrget: the carbonic acid they form during darkness and common da-light."

The solution of this question I have attempted, and I hope one day to give a satisfactory answer to it.

And, sir, I presume I may also add that I have attempted a solution of the above question, particularly in the third and fourth experiment, as related in my first paper, in which the plants, inclosed in receivers, were exposed not to air vitiated by the breathing of animals; but to common air, during darkness, common day-light, and sunshme; the former of the above for seven successive days, and the latter for there successive days, in both of which experiments it did not appear to me that the plants had the power during sunshine to reconvert into oxygen the carbonic acid they formed during darkness and common daylight.

From these observations it appears that the subject is yet a controverted one, and that there are celebrated authors of the present day whose opinions are at variance with each other; and I think it is meritorious in any one, amid this conflict of contending opinions, to commumicate his researches to the eommon stock; and most certainly I anxiously wait the coming day on which W.H. G. has pronised to give to the public the results of his critical experiments. But should he be inclined to make any further remarks on me, and expect an answer, he will please tp conclude with his real name and address.

Dorset-street, Oct. 20, 1817.

$$
\text { I am, sir, yours \&c. }
$$

P.S. Since I last addressed you, I have found that the small pustules on the ice-plant contain a very considerable portion of muriatic acid; but the smallness of the quantity of the fluid which they contain has as yet prevented ne from ascertaining with what it is combined. I am not aware that any one has hitherto noticed it.

LVIII. Acknowledgements to Mr. Westgarth Forster; further Geological Queries, on the Basaltic Strata of Durham and Northumberland: and Suggestions regarding the Situation of the Granite Patches of the North of England, in its Series. of Strata. By A Correspondent.

$$
\text { To Mr. Tilloch. }
$$

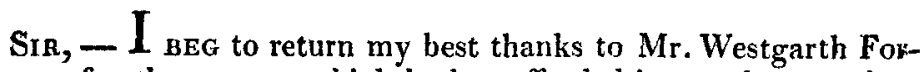
ster, for the answers which he has afforded in your last number, page 216, to my 2d Question, as to the true character and position 